\title{
Organizational Change and Skill Accumulation
}

\author{
Eve Carolia ${ }^{a}$, Nathalie Greenan ${ }^{b}$ and \\ Dominique Guellec ${ }^{c}$ \\ ('aNRA-LEA and CEPREMAP, ${ }^{\mathrm{b}}$ Centre d'Etude de l'Emploi and ${ }^{\mathrm{c} O E C D / S T I}$ )
}

We model the links between skills and changes in work organization. As the proportion of skilled workers increases, the economy travels through a sequence of organizational equilibria. We show that as the relative supply of skills increases the organization of work becomes more decentralized. Both skilled and unskilled workers become more autonomous and perform a wider range of tasks: decentralization spreads across firms at the expense of the old centralized organization based on a strict division of labor. Moreover, as firms switch to decentralization, their employment structure becomes more homogeneous and wage inequality stops decreasing. These predictions are compared with empirical evidence based on French establishment-level data and we find support for both of them. This suggests that the long-term increase in the skill level of the workforce may have been one important factor driving the recent introduction of new work practices by a large number of firms.

\section{Introduction}

For several years now the organization of work inside firms has been undergoing tremendous changes. The labels given to innovative organizational practices are quite diverse: re-engineering, just in time, delayering, lean production, flexibility, empowerment, outsourcing, etc. Beyond the variety of ways taken by firms and the variety of strategies they carry out these labels signal a new trend towards more autonomy of workers as middle layers of the hierarchy are suppressed (OECD, 1999). The organization of work is becoming more decentralized, as has been documented in many empirical studies: Osterman (1994) for US manufacturing, NUTEK (1996) for the Swedish economy and Greenan (1996a,b) and Greenan and Guellec (1998) for French manufacturing. As hierarchical layers disappear, rank and file workers have to take decisions that used to be taken by their boss: dealing

(C) Oxford University Press 2001 
with customers, fixing technical hitches and deciding on inventories. Between 1988 and 1993 80\% of French manufacturing firms with more than 50 employees have changed the organization of their production process. Thirty-one per cent of these reorganized firms have reduced their number of hierarchical layers and $43 \%$ have introduced autonomous teamwork. After reorganization blue collar workers have become responsible for controlling the quality of products in $37 \%$ of firms and for proposing process improvements in $40 \%$ of them (Greenan, 1996a). French labor force surveys tell a similar story. In $198738 \%$ of skilled blue collar workers and $21 \%$ of unskilled ones had to fix hitches by themselves. These shares reached $46 \%$ and $31 \%$, respectively, in 1993 (Aquain et al., 1994). In 1991 42\% of skilled blue collar workers had some direct contact with customers, as compared with $47 \%$ in 1993. A parallel evolution is the rise in the share of small and medium sized firms in total employment, as documented by the decreasing weight of Fortune 500 firms in the US labor force. This means that a growing number of workers are directly faced with the market, having to act and react as technology and market conditions change and, hence, having to be autonomous. With more decentralized firms and more small businesses the organizational picture of western economies is changing. This is to be contrasted with the previously dominant scheme, based on a Taylorist tradition, which emphasized the advantage of setting precise norms and closely monitoring workers through their specialization in conception or execution activities (Braverman, 1974). Why has there been such a revolution in the organization of firms?

The economic literature about organizational change has so far provided four main explanations for this phenomenon. The first is based on technical change. New technologies allow more efficient processing of information, both in terms of speed and of cost. It is one key role of hierarchies that is challenged by computers and communication technologies: networks increasingly replace bosses with direct interactions between workers (Bolton and Dewatripont, 1994). A second explanation underlines the role of market instability. In a world characterized by a highly uncertain demand as well as strong market volatility firms' competitiveness depends heavily on their ability to react rapidly and costlessly to unforeseen events. In this respect, decentralized work organizations prove more efficient than hierarchical, bureaucratic ones (Aoki, 1986). Third is a shortening in the length of batches, which reduces the economies of scale arising from an organization based on a strict division of labor. Shorter batches require a high adaptability of the labor force, in order to ensure quick learning by doing (Greenan and Guellec, 1994). Finally, it has been argued (Aoki, 1990; Boyer, 1991) that the 
strengthening of employees' democratic aspirations is challenging hierarchical relationships at the root of the centralized model.

The model presented here puts forward a fifth explanation, namely skill accumulation, i.e. the increase in the skill or educational level of the workforce. The influence of skills upon work organization has been widely acknowledged in recent literature (Marsden and Ryan, 1991; Soskice, 1993). The skill level of the labor force is seen as impacting directly on the organization of firms. Skill is about mastering complex issues. For workers to be autonomous in a complex economy they must be skilled, otherwise they are likely to make wrong decisions, based on a poor understanding of the issues at stake. Unskilled workers will then perform jobs that are free of complex decisions, while such decisions will be taken by skilled workers.

Kremer (1993) and Kremer and Maskin (1996) also focus on the relationships between the level of education in the economy, the structure of skills within firms and wage inequality. However, they do not explicitly model organizational change. They show that if production takes place according to an o-ring function there is some cross-matching of skills within firms as long as skill dispersion remains below a certain threshold. Acemoglu (1999) displays similar results, adding that the probability of separating equilibria increases with the proportion of skilled workers in the economy. Thesmar and Thoenig (2000) model a relationship between skills, technical change and organizational change. A more highly skilled labor force leads to faster technical change and hence to changes in work organization aimed at reducing the cost of implementation of the new technology. Lindbeck and Snower (1996) go deeper into what organization actually is. The organizational pattern they display is close to ours: Taylorist firms specialize workers by occupation, whereas in holistic firms workers rotate among different tasks. However, the authors focus on multi-tasking rather than autonomy and on horizontal rather than vertical division of work. Moreover, they draw no link between the nature of tasks and the skills of workers. As a result, wage inequality arises between workers attached to different types of firms, whatever their skills. Moreover, as in Kremer and Maskin, changes in organization are fostered by external shocks. Our model also generates a higher homogeneity of the in-firm skill structure as well as a pattern for wage inequality, but these result from endogenous organizational change. This is driven by a long-lasting trend in western economies: the increase in the supply of skilled workers.

An explanation of organizational change based on accumulation of skills does not necessarily exclude some influence of other factors, notably those mentioned above. More precisely, changes in the skill level of the labor force 
may contribute to these factors. Technology is closely related to organization, so that in many cases these two aspects can hardly be disentangled, such as for the assembly line. Information and communication technologies have been shown to require more highly skilled workers and a new organization altogether. In a world where the direction of technical change is endogenous, i.e. where technical change enhances the productivity of skills (Acemoglu, 1998), the two explanations can be reconciled: the increasing availability of skilled workers generates both a technology and an organization that demand more skills. Also, skilled workers are probably more demanding in terms of participation in decision making ('democratic aspirations') than are unskilled ones. Demand for more differentiated goods, and hence smaller batches, comes from higher income customers, i.e. generally those endowed with more skills.

We propose a simple model based on comparative advantages and relating organizational change to skill accumulation. Our economy is composed of two types of workers: 'skilled workers' who have been through the education system up to the end of secondary school and 'unskilled workers' who have not. We assume that secondary education strengthens primary education attainments in reading, writing and calculation, while, at the same time, developing abilities in synthesis, analysis and discussion. Our definition of skills is thus restrictive, focused on formal knowledge transmitted through the education system.

Final production requires two parallel activities on the part of workers: knowledge and raw labor production. Knowledge is about the best way to carry out tasks, to sequence them in time and to react to technical hitches or signals coming from the demand side. It is not given to the firm but produced on site, through conception activities that are time consuming. Once production plans and tasks are designed some raw labor is required in order to perform them. This is provided through execution activities, which consist of the implementation of the whole range of tasks designed through conception activities.

The organization of work is characterized by the way skilled and unskilled labor combine together in order to produce knowledge and raw labor. Two alternative modes of organization may be chosen by firms: a centralized mode (the $\mathrm{C}$ model) and a decentralized one (the $\mathrm{D}$ model). ${ }^{1}$ The central feature of the $\mathrm{C}$ model rests on a clear separation between conception and execution activities. Skilled workers are specialized in knowledge production with knowledge taking the form of norms, orders and assignments. These are issued to unskilled workers who are specialized in execution activities. Such an organization makes full use of the comparative advantage of skilled

\footnotetext{
${ }^{1}$ This approach is in many ways similar to Greenan and Guellec (1994), although the production functions are quite different.
} 
workers in conception activities. Firms can also opt for a decentralized organization, the D model. In this case vertical division of labor is replaced by autonomy and self-responsibility of workers: whatever their skills, workers have to carry out execution tasks along with conception ones.

We opt here for embedding organization in the production function. The characteristics of work organization are captured by the functional form itself, rather than, as is usually the case, by a factor added to the production function, the so-called 'organizational capital'. Such a factor captures the economic value of an organizational pattern, its contribution to productivity, but gives no clue as to how the production factors are arranged so as to work together. This is clearly insufficient to reflect the deep structural changes which may occur at a microeconomic or plant level when the organization of work is modified. When a firm changes its technology or organization this often generates a discontinuity. This discontinuity is not only of a quantitative nature. It is also a qualitative change, involving specific trade-offs: the gains arising from the switch are usually partly outweighed by losses, even though the overall outcome proves positive. There is creative destruction, for organization as well as for technology. Our approach allows us to account for those qualitative, not only quantitative, changes in organizational modes.

Firms choose their organization so as to maximize profit. This results in an organizational regime characterized by a distribution of firms over the two modes of organization, C and D. One key outcome of the paper is that the very nature of the organizational regime which eventually prevails depends on the supply of skilled and unskilled labor. In turn, the organizational regime affects the demand for each category of workers, hence their relative price. We thus study the dynamics of wages and organizational change as skills accumulate in the economy.

A first result is that as the supply of skilled workers increases the economy goes through a path of organizational change. When unskilled labor is abundant the organizational regime is mixed: decentralized and centralized firms coexist in the economy. Skilled labor, which is scarce, is all employed in centralized firms where it is specialized in knowledge production. In contrast, unskilled workers participate in both centralized and decentralized organizations. As the relative supply of skilled workers increases this gives rise to a first phase of growing centralization with an increasing proportion of the labor force being employed in centralized firms. In a second phase the centralized organization dominates in the economy: all workers, whatever their skills, are employed in centralized firms. In a third phase skilled labor has become abundant enough for firms to start using it both in conception and execution activities. This leads to the spreading of a decentralized mode 
of organization at the expense of the old centralized system, with the former finally overtaking in the whole economy.

The pattern of organizational change displayed by our approach is broadly consistent with historical evidence. Over the 19th century the so-called Taylorist mode of organization, also referred to as 'the American system of manufacturing' (although somewhat excessively since it also has European roots), steadily developed in Western countries (Chandler, 1962), undermining craft production. It undoubtedly culminated in the middle of the 20th century with the building up of large hierarchical firms characterized by a strong division of labor. In contrast, over the past decades a move towards decentralization has taken place, leading to a stop in the bureaucratization process of Taylorist firms and to the development of highly skilled enterprises through outsourcing and firm creation. The shift from decentralized craft production to centralized industrial production had induced great changes in the working routines of the unskilled. The separation between conception and execution activities had led to some dequalification of their work and their specialization in execution activities. This move was one of the forces that drove industrialization since if organization had remained decentralized, manufacturing would not have sucked up the largest share of the labor force, still unskilled. In contrast, the shift experienced nowadays implies that skilled workers have to modify the way they work as they progressively lose their hierarchical position: decision making is shared between a greater number of skilled workers who have to handle a wider range of tasks within flatter organizations.

A second result is that as decentralization starts to spread in the economy, wage inequality across skilled and unskilled workers stops decreasing. In a centralized regime the productivity of skilled workers decreases as they become more numerous, which brings about a steady reduction in the skilled-unskilled wage gap. This is no longer the case as decentralization develops, so that the reduction in wage inequality is stopped. This is in line with empirical evidence from OECD countries where the downward trend in skill-related wage inequalities experienced throughout the 1970s was interrupted by the beginning of the 1980s (Aghion et al., 1999). A series of works by Goldin and Katz (1999, for instance) shows that in the USA the wage gap between skilled and unskilled workers decreased throughout the 20th century up to the early 1980s, before widening in the last two decades. For other countries the available evidence for the after war period displays similar features, although there was only a leveling off and no widening of the wage gap in the 1980s, except in the UK (see Atkinson, 1997).

A third result concerns the nature of the skill mix within firms. In the first 
organizational phase the share of skilled workers in the total labor force of centralized firms is constant and decentralized firms employ only unskilled workers. When the centralized model dominates in the economy the share of skilled workers starts to grow within $\mathrm{C}$ firms. In this second phase crossmatching of skills within firms reaches its highest level. In the third stage the proportion of skilled workers in centralized firms stabilizes at a level which is higher than that observed in the first phase and decentralized firms start employing a growing number of skilled workers, who are no longer associated with the unskilled in the production process.

The paper is organized as follows. Section 2 presents the model. Section 3 works out the patterns of organizational change and wage inequality as the relative supply of skilled workers increases in the economy. Section 4 tests the two main predictions of the model using French establishment-level data. Preliminary support is found for both of them. Section 5 concludes.

\section{The Model}

We consider an economy in which firms produce one homogeneous good, consumed by workers. Product and labor markets are competitive. The working population is of fixed size $n$. Each firm uses two primary inputs (skilled and unskilled workers) and experiences constant returns to scale. Production requires two parallel activities on the part of workers: conception (knowledge production) and execution (direct or raw labor production). The production process combines knowledge $(m)$ and raw labor $(l)$ in the following manner (generic production function):

$$
y_{\mathrm{t}}=A m_{\mathrm{t}}^{\alpha} l_{\mathrm{t}}^{1-\alpha}
$$

where $y_{\mathrm{t}}$ denotes output and $A$ is a technical progress parameter (assumed to be constant in the following).

We assume that skilled workers are more productive than unskilled ones in both knowledge and raw labor production, but that their comparative advantage is bigger at conception activities. Education particularly affects the ability to analyze complex sets of data, as well as to draw conclusions from various, and sometimes brand new, information. As a consequence, the capacity of skilled workers to conceive and adapt plans of production as well as task designs is higher than that of unskilled workers. Formally:

$$
\delta^{\mathrm{s}}>\delta^{\mathrm{u}}
$$


where $\delta^{s}$ and $\delta^{u}$ denote the respective productivity of skilled and unskilled workers in knowledge production. Because they can better analyze production tasks, skilled workers are also more able in execution activities. Using the words of Lindbeck and Snower (1996), the 'informational complementarity' between conception and execution tasks is stronger for skilled than for unskilled workers:

$$
\gamma>\gamma^{u}
$$

where $\gamma^{\beta}$ and $\gamma^{\mathrm{u}}$ are the respective productivity of skilled and unskilled workers in execution activities. Nevertheless, the related productivity gap between skilled and unskilled workers is assumed to be wider in conception than in execution activities. This builds a relative advantage for skilled workers in knowledge production:

$$
\left(\delta^{s} / \delta^{u}\right)>\left(\gamma^{s} / \gamma^{u}\right)
$$

We define the organization of work as an allocation of both types of workers between conception and execution activities. Production can be organized in two ways: one in which workers are specialized in a single activity and one in which they are involved in both types of tasks. In the first model the workforce is allocated to an activity according to its skills. Work is vertically divided and the corresponding organizational model is said to be centralized. In the second model work is vertically integrated and its organization is said to be decentralized.

\subsection{The Centralized (C) Model}

In the $\mathrm{C}$ model the combination of knowledge and raw labor depicted by equation (1) takes place at the level of the firm. Workers are either knowledge processors or raw material processors. Knowledge workers take decisions concerning task design and production plans and monitor their implementation. They are both experts and bosses. Execution workers are in charge of direct production: they provide raw labor and comply with orders issued by the hierarchy.

Each type of worker is specialized in the activity in which her/his comparative advantage is bigger. So, skilled workers are allocated to conception and unskilled workers to execution activities. Omitting subscript $t$, the production function in the centralized model writes: 


$$
y_{\mathrm{c}}=A m_{\mathrm{c}}^{\alpha} l_{\mathrm{c}}{ }^{1-\alpha}
$$

where $y_{c}$ denotes output, $m_{c}$ knowledge and $l_{c}$ raw labor. Knowledge and raw labor are defined as follows:

$$
\begin{aligned}
& m_{\mathrm{c}}=\delta^{\mathrm{s}} n^{\mathrm{s}}{ }_{\mathrm{c}} \\
& l_{\mathrm{c}}=\gamma^{\mathrm{u}} n^{\mathrm{u}}{ }_{\mathrm{c}}
\end{aligned}
$$

where $n^{\mathrm{s}}$ and $n^{\mathrm{u}}{ }_{\mathrm{c}}$ are, respectively, the number of skilled and unskilled workers employed in the $\mathrm{C}$ model. The amount of knowledge that is produced depends on the effectiveness of skilled workers in conception activities $\left(\delta^{s}\right)$, while the amount of raw labor available for direct production depends on the effectiveness of unskilled workers in execution activities $\left(\gamma^{\mu}\right)$. Finally, the production function writes:

$$
y_{\mathrm{c}}=A\left(\boldsymbol{\delta}^{\mathrm{s}} n_{\mathrm{c}}^{\mathrm{s}}\right)^{\alpha}\left(\gamma^{\mathrm{u}} n_{\mathrm{c}}^{\mathrm{u}}\right)^{1-\alpha}
$$

\subsection{The Decentralized (D) Model}

In the $\mathrm{D}$ model workers are not specialized in a task. They participate both in conception and execution activities so that the generic production function depicted by equation (1) is embedded in each worker. Let $y_{\mathrm{d}}^{\mathrm{i}}$ denote the production of an $i$-type worker $(i=u ; s)$ in the $\mathrm{D}$ model:

$$
y_{\mathrm{d}}^{i}=A\left(m_{\mathrm{d}}^{i}\right)^{\alpha}\left(l_{\mathrm{d}}^{i}\right)^{1-\alpha}
$$

The amount of knowledge produced by a worker of type $i\left(m_{\mathrm{d}}^{i}\right)$ depends both on the fraction of time devoted to conception activities $\left(\mu^{i} ; 0 \leq \mu^{i} \leq 1\right)$ and on his effectiveness in knowledge production $\left(\delta^{i}\right)$. Formally:

$$
m_{\mathrm{d}}^{i}=\mu^{i} \delta^{i}
$$

The remaining fraction of time $\left(1-\mu^{i}\right)$ is dedicated to execution activities, with productivity $\gamma^{i}$. Hence, the amount of raw labor entering final production is given by:

$$
l_{\mathrm{d}}^{i}=\left(1-\mu^{i}\right) \gamma^{i}
$$


Aggregate production in the $\mathrm{D}$ model is just the sum of workers' output:

$$
\begin{gathered}
y_{\mathrm{d}}=\sum_{i} y_{\mathrm{d}}^{i} \cdot n_{\mathrm{d}}^{i} \\
\Leftrightarrow y_{\mathrm{d}}=A\left\{( \delta ^ { \mathrm { s } } \mu ^ { \mathrm { s } } ) ^ { \alpha } \left[\gamma^{s}\left(1-\mu^{s}\right]^{1-\alpha} n_{\mathrm{d}}^{\mathrm{s}}+\left(\delta^{\mathrm{u}} \mu^{\mathrm{u}}\right)^{\alpha}\left[\gamma^{\mathrm{u}}\left(1-\mu^{\mathrm{u}}\right]^{1-\alpha} n^{\mathrm{u}}{ }_{\mathrm{d}}\right\}\right.\right.
\end{gathered}
$$

where $n_{\mathrm{d}}^{\mathrm{s}}$ and $n_{\mathrm{d}}^{\mathrm{u}}$ denote the number of skilled and unskilled workers employed in the decentralized model, respectively. The above specification accounts for two main features of a decentralized work organization: the autonomy of workers, as opposed to the hierarchical structure of the $\mathrm{C}$ model, and the greater variety of tasks they perform. Whatever their skills, workers decide on their own how to carry out direct production tasks. They do so during the fraction of time allocated to conception activities. In the $\mathrm{D}$ model knowledge is less formal than in the $\mathrm{C}$ model because it does not need to be translated into norms, orders or assignments. Moreover, since work is vertically integrated, each category of workers performs a wider range of tasks.

Firms allocate workers' time between conception and direct production so as to maximize profit:

$$
\left\{\begin{array}{l}
\max _{\mu^{i}} \pi_{\mathrm{d}}^{i}=\sum_{i=\mathrm{u}, \mathrm{s}} A\left(\delta^{i} \mu^{i}\right)^{\alpha}\left[\gamma^{i}\left(1-\mu^{i}\right)\right]^{1-\alpha} n_{\mathrm{d}}^{i}-w^{\mathrm{s}} n_{\mathrm{d}}^{\mathrm{s}}-w^{\mathrm{u}} n_{\mathrm{d}}^{\mathrm{u}} \\
\operatorname{sc} 0 \leq \mu^{i} \leq 1
\end{array}\right.
$$

Solving this program yields $\mu^{i}=\alpha \forall i$, which implies that time allocation is identical for both skilled and unskilled workers, as it depends only on the elasticity of production with respect to conception activities, $\alpha$. Hence, the production function in the $\mathrm{D}$ model can be rewritten as:

$$
y_{\mathrm{d}}=A \alpha^{\alpha}(1-\alpha)^{1-\alpha}\left[\left(\delta^{s}\right)^{\alpha}\left(\gamma^{s}\right)^{1-\alpha} n_{d}^{\mathrm{s}}+\left(\delta^{\mathrm{u}}\right)^{\alpha}\left(\gamma^{\mathrm{u}}\right)^{1-\alpha} n^{\mathrm{u}}{ }_{\mathrm{d}}\right]
$$

\section{Skill Accumulation and Organizational Change}

We assume that the number of skilled workers available in the economy, $n^{\mathrm{s}}$, is exogenous and growing at a constant pace:

$$
n_{t}^{\mathrm{s}}-n_{t-1}^{\mathrm{s}}=\Delta n^{\mathrm{s}}>0 \forall n_{t-1}^{\mathrm{s}}<n
$$


We proceed through a two step solution. First, we assess firms' organizational choice for given levels of the skilled-unskilled relative wage. Then we determine market wages under each organizational regime, assuming that both skilled and unskilled labor markets are in equilibrium.

\subsection{Relative Wages and Organizational Choices}

A firm can choose to be either centralized or decentralized. It will do so in order to minimize the average cost of production. Under centralization this is:

$$
A C_{\mathrm{c}}=1 / A\left(w^{\mathrm{s}} / \alpha \delta^{\mathrm{s}}\right)^{\alpha}\left[w^{\mathrm{u}} /(1-\alpha) \gamma^{\mathrm{u}}\right]^{1-\alpha}
$$

This mode of organization is denoted $\mathrm{C}(u, s)$ since the organization of work is centralized and production requires both skilled and unskilled workers.

Under decentralization both types of workers are perfect substitutes in the production process. The effective cost $\left(w_{\mathrm{e}}^{\mathrm{i}}\right)$ of each type of worker $(i=u ; s)$ is given by the ratio of market wage to productive efficiency:

$$
w_{\mathrm{e}}^{i}=w^{i} /\left[A \alpha^{\alpha}(1-\alpha)^{1-\alpha}\left(\delta^{i}\right)^{\alpha}\left(\gamma^{j}\right)^{1-\alpha}\right]
$$

A D firm will always choose the category of workers that proves cheaper according to equation (14). Three types of decentralized organizations are then possible: decentralization with only unskilled workers $\mathrm{D}(u)$, decentralization with only skilled workers $\mathrm{D}(s)$ and decentralization with both categories being employed $\mathrm{D}(u, s)$. Although the $\mathrm{D}(u, s)$ configuration with a mixed labor force is conceivable, we will see that it is never chosen because it is always dominated by the $\mathrm{C}(u, s)$ configuration. The average costs of $\mathrm{D}(u)$ and $\mathrm{D}(s)$ are, respectively:

$$
\begin{aligned}
& A C_{\mathrm{D}(\mathrm{u})}=w^{\mathrm{u}} /\left[A \alpha^{\alpha}(1-\alpha)^{1-\alpha}\left(\delta^{\mathrm{u}}\right)^{\alpha}\left(\gamma^{\mathrm{u}}\right)^{1-\alpha}\right] \\
& A C_{\mathrm{D}(\mathrm{s})}=w^{\mathrm{s}} /\left[A \alpha^{\alpha}(1-\alpha)^{1-\alpha}\left(\delta^{s}\right)^{\alpha}\left(\gamma^{s}\right)^{1-\alpha}\right]
\end{aligned}
$$

In both $\mathrm{D}(u)$ and $\mathrm{D}(s)$ the labor force is more autonomous and more homogeneous than in $\mathrm{C}(u, s)$. However, $\mathrm{D}(u)$ and $\mathrm{D}(s)$ differ according to the skill level of their workforce. $\mathrm{D}(u)$ can be seen as craft organization, resting on unskilled workers who carry out the production process from its beginning to its end. In $\mathrm{D}(u)$ the fact that workers are unskilled does not imply that they embed no useful knowledge about the production process. As they participate 


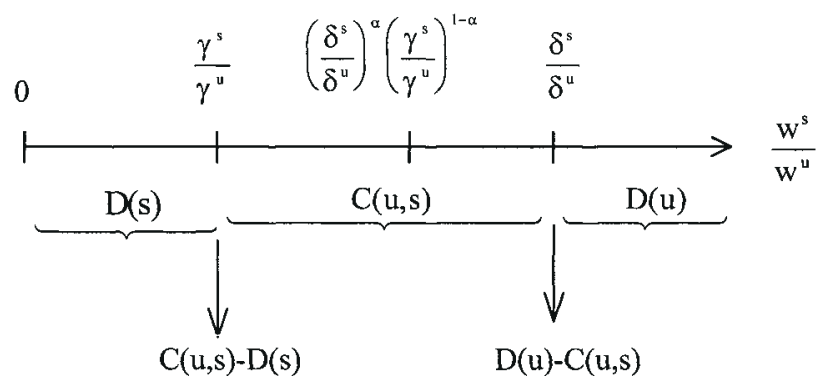

FIGURE 1. Firm's organizational choice.

into conception activities they incorporate practical knowledge acquired on the job, through experience. In this case 'unskilled' may seem improper, but it simply indicates that the workers' knowledge does not come from formal education. $\mathrm{D}(s)$ is a decentralized organization of a different type as all the workers it employs are skilled, i.e. they have been through the education system. This type of organization is to be found in many areas of the service sector. Indeed, lawyers, consultants, accountants, researchers, software programmers, etc. often work in firms where the workforce is homogeneously skilled.

In order to decide on their work organization, firms must compare separately the average cost of production in each of the decentralized modes, $\mathrm{D}(u), \mathrm{D}(s)$ and $\mathrm{D}(u, s)$, with that under $\mathrm{C}(u, s)$. The outcome of this comparison is summarized in Figure 1.

As far as technical efficiency is concerned $\mathrm{D}(u), \mathrm{C}(u, s)$ and $\mathrm{D}(s)$ can be ranked as follows: $\mathrm{D}(u)<\mathrm{C}(u, s)<\mathrm{D}(s)$. Skilled workers being more productive in both knowledge and direct production, it is technically more efficient to have them in both activities, $\mathrm{D}(s)$, than in one, $\mathrm{C}(u, s)$, which is more efficient than employing unskilled workers in both tasks, $\mathrm{D}(u)$. However, from an economic point of view the gain in terms of performance brought about by skilled workers has to be balanced against the additional wage cost they induce. If the additional cost $\left(w^{\mathrm{s}} / w^{\mathrm{u}}\right)$ is lower than the gain in both knowledge $\left(\delta^{\mathrm{s}} / \delta^{\mathrm{u}}\right)$ and raw labor $\left(\gamma^{\mathrm{s}} / \gamma^{\mathrm{u}}\right)$ activities the firm employs only skilled workers and assigns them to both types of activities, $\mathrm{D}(s)$. If the additional cost is lower than the gain in conception activities but higher than that in direct production the firm will choose to be centralized with skilled workers employed in knowledge production and, correspondingly, unskilled workers employed in execution activities, $\mathrm{C}(u, s)$. When efficiency gains do not compensate for the cost of employing skilled labor the firm chooses to employ only unskilled workers and is then decentralized, $\mathrm{D}(u)$. Finally, when 
$w^{s} / w^{\mathrm{u}}=\gamma^{s} / \gamma^{\mathrm{u}}\left(\right.$ respectively $\left.\delta^{\mathrm{s}} / \delta^{\mathrm{u}}\right)$ firms are indifferent between $\mathrm{D}(s)$ and $\mathrm{C}(u, s)$ [respectively $\mathrm{D}(u)$ and $\mathrm{C}(u, s)$ ].

No firm ever chooses to be decentralized with both types of workers, $\mathrm{D}(u, s)$, because this mode of organization is always more costly than a fully centralized one. A firm is ready to hire both skilled and unskilled workers in a decentralized organization only if

$$
A C_{\mathrm{D}(\mathrm{u})}=A C_{\mathrm{D}(\mathrm{s})} \Leftrightarrow w^{\mathrm{s}} / w^{\mathrm{u}}=\left(\delta^{\mathrm{s}} / \delta^{\mathrm{u}}\right)^{\alpha}\left(\gamma^{s} / \gamma^{\mathrm{u}}\right)^{1-\alpha}
$$

However, if this happens to be the case $\mathrm{C}(u, s)$ is more profitable since the gain in terms of effectiveness due to hiring a skilled worker is $\delta^{s} / \delta^{u}$ in $C(u, s)$ as compared with $\left(\delta^{s} / \delta^{u}\right)^{\alpha}\left(\gamma^{s} / \gamma^{u}\right)^{1-\alpha}$ in $\mathrm{D}(u, s)$. Given that $\delta^{s} / \delta^{u}>\gamma^{s} / \gamma^{u}, \delta^{s} / \delta^{u}>$ $w^{s} / w^{u}=\left(\delta^{s} / \delta^{u}\right)^{\alpha}\left(\gamma^{s} / \gamma^{u}\right)^{1-\alpha}$. So, whatever the value of $n^{s}, \mathrm{D}(u, s)$ is always dominated by $\mathrm{C}(u, s)$.

From this sequence of organizational choices one can derive the patterns of organizational change as the relative supply of skilled workers increases in the economy.

\subsection{Patterns of Organizational Change}

Setting skilled and unskilled labor markets to equilibrium yields:

$$
\begin{aligned}
& n_{\mathrm{c}}^{\mathrm{s}}+n_{\mathrm{d}}^{\mathrm{s}}=n^{\mathrm{s}} \\
& n^{\mathrm{u}}+n_{\mathrm{d}}^{\mathrm{u}}=n^{\mathrm{u}} \\
& n^{\mathrm{u}}+n^{\mathrm{s}}=n
\end{aligned}
$$

where $n$ denotes the whole working population. Under pure centralization the relative wage is given by:

$$
w^{\mathrm{s}} / w^{\mathrm{u}}=(\alpha / 1-\alpha)\left[\left(n / n^{\mathrm{s}}\right)-1\right]
$$

Combining (20) with the threshold values of $w^{\mathrm{s}} / w^{\mathrm{u}}$ given in Figure 1 yields the pattern of organizational choices made by firms as $n^{s}$ varies (see Figure 2) with:

$$
n^{\mathrm{s}}{ }_{1}=n /\left\{1+[(1-\alpha) / \alpha] \cdot \delta^{\mathrm{s}} / \delta^{\mathrm{u}}\right\}
$$

and 


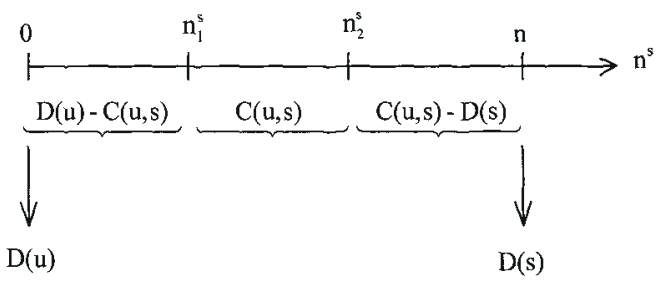

FIGURE 2. Pattern of organizational change.

$$
n_{2}^{\mathrm{s}}=n /\left\{1+[(1-\alpha) / \alpha] \cdot \gamma^{\mathrm{s}} / \gamma^{\mathrm{u}}\right\}
$$

When all workers are unskilled $\left(n^{\mathrm{s}}=0\right)$ the firm obviously chooses to be decentralized and the prevailing organizational regime is $\mathrm{D}(u)$.

When some workers become skilled a centralized model with strict vertical division of labor $\mathrm{C}(u, s)$ becomes possible. We show that when the number of skilled workers in the economy is lower than $n^{\mathrm{s}}{ }_{1}$ equilibrium on the labor market maintains the relative wage $w^{\mathrm{s}} / w^{\mathrm{u}}$ at a constant level $\delta^{\mathrm{s}} / \delta^{\mathrm{u}}$, so that any firm is indifferent between $\mathrm{D}(u)$ and $\mathrm{C}(u, s){ }^{2}$ The aggregate employment structure is then:

$$
\begin{gathered}
n^{\mathrm{s}}=n^{\mathrm{s}} \\
n^{\mathrm{u}}{ }_{\mathrm{c}}=[(1-\alpha) / \alpha]\left(\delta^{\mathrm{s}} / \delta^{\mathrm{u}}\right) n^{\mathrm{s}} \\
n^{\mathrm{u}}{ }_{\mathrm{d}}=n-n^{\mathrm{s}}\left(1+\frac{1-\alpha}{\alpha} \frac{\delta^{\mathrm{s}}}{\delta^{\mathrm{u}}}\right)
\end{gathered}
$$

In this range of values of $n^{\mathrm{s}}$ skilled workers are so scarce that their wage would be extremely high if all workers were employed in the centralized sector $\left(w^{\mathrm{s}} / w^{\mathrm{u}}\right.$ $\left.>\delta^{s} / \delta^{u}\right)$. The gain in effectiveness they bring about in conception activities $\left(\delta^{\mathrm{s}} / \delta^{\mathrm{u}}\right)$ would not cover the additional cost they would then induce $\left(w^{\mathrm{s}} / w^{\mathrm{u}}\right)$. A wholly decentralized structure with only unskilled workers, $\mathrm{D}(u)$, is also inefficient since skilled workers would remain unemployed. The efficient organizational structure is then mixed. Two sectors coexist in the economy: a centralized sector which hires all skilled workers along with some unskilled (according to a ratio determined by profit maximization) and a decentralized

\footnotetext{
${ }^{2}$ The proof is as follows. If $w^{\mathrm{s}} / w^{\mathrm{u}}>\delta^{\mathrm{s}} / \delta^{\mathrm{u}}$, according to Figure 1 the firm would choose $\mathrm{D}(u)$. Then $w^{\mathrm{s}}$ $=0$, so that $w^{\mathrm{s}}<w^{\mathrm{u}}$, which contradicts the above assumption that $w^{\mathrm{s}} / w^{\mathrm{u}}>\delta^{\mathrm{s}} / \delta^{\mathrm{u}}>1$. Accordingly, if $w^{\mathrm{s}} / w^{\mathrm{u}}$ $<\delta^{\mathrm{s}} / \delta^{\mathrm{u}}$ the firm chooses $\mathrm{C}(u, s)$. But in this case, for values of $n^{\mathrm{s}}<n^{\mathrm{s}}, w^{\mathrm{s}} / w^{\mathrm{u}}>\delta^{\mathrm{s}} / \delta^{\mathrm{u}}$, which contradicts the above assumption. Hence, $w^{\mathrm{s}} / w^{\mathrm{u}}=\delta^{\mathrm{s}} / \delta^{\mathrm{u}} \forall n^{\mathrm{s}}<n^{\mathrm{s}}{ }_{1}$. QED.
} 
one which hires all remaining unskilled workers. The corresponding organizational regime is labeled $\mathrm{D}(u)-\mathrm{C}(u, s)$. As $n^{\mathrm{s}}$ increases towards $n_{1}^{\mathrm{s}}$ the proportion of the workforce employed in the centralized sector increases at the expense of the decentralized one: the centralized mode of organization spreads over in the economy. It is this progressive shift towards the $\mathrm{C}(u, s)$ model that induces constancy of the relative wage in the $\mathrm{D}(u)-\mathrm{C}(u, s)$ regime. In the $\mathrm{D}(u)$ model the marginal productivity of unskilled workers is constant, but in the centralized one the vertical interdependency between skilled and unskilled workers generates a complementarity. As the share of skilled workers increases so does the marginal productivity of unskilled workers employed in the $\mathrm{C}$ model. So, an increasing fraction of them is hired in centralized firms up to the optimal ratio $n_{c}^{\mathrm{s}} / n^{\mathrm{u}}{ }_{\mathrm{c}}=\alpha \delta^{\mathrm{u}} /(1-\alpha) \delta^{\mathrm{s}}$, thus allowing the relative wage to be constant: $w^{\mathrm{s}} / w^{\mathrm{u}}=\delta^{\mathrm{s}} / \delta^{\mathrm{u}}$.

When $n_{1}^{\mathrm{s}}<n^{\mathrm{s}}<n^{\mathrm{s}}$ skilled workers are numerous enough for the whole labor force to be profitably employed in centralized firms. The aggregate employment structure simply writes as:

$$
\begin{gathered}
n^{\mathrm{s}}=n^{\mathrm{s}} \\
n^{\mathrm{u}}{ }_{\mathrm{c}}=n-n^{\mathrm{s}}
\end{gathered}
$$

The relative wage varies according to equation (20). It has gone down $\left(\gamma^{\gamma} / \gamma^{\mathrm{u}}\right.$ $<w^{\mathrm{s}} / w^{\mathrm{u}}<\delta^{\mathrm{s}} / \delta^{\mathrm{u}}$ ) so that the additional cost induced by skilled workers is now lower than the gain in effectiveness they bring in conception activities $\left(\delta^{\mathrm{s}} / \delta^{\mathrm{u}}\right)$, though still higher than the gain they would bring to direct production $\left(\gamma / \gamma^{\prime}\right)$. It is thus optimal for firms to choose a centralized organization, with skilled workers specialized in knowledge production and unskilled workers specialized in execution. The corresponding organizational regime is denoted $\mathrm{C}(u, s)$.

When the number of skilled workers in the economy becomes greater than $n^{\mathrm{s}}{ }_{2}$ another mixed regime prevails, where $\mathrm{D}(s)$ plays a part comparable to that played by $\mathrm{D}(u)$ in the $\mathrm{D}(u)-\mathrm{C}(u, s)$ regime: the skilled workforce is now abundant whereas unskilled workers are scarce. The equilibrium on the labor market leads to a constant relative wage, $w^{\mathrm{s}} / w^{\mathrm{u}}=\gamma^{\mathrm{s}} / \gamma^{\mathrm{u}}$, for which firms are indifferent between $\mathrm{C}(u, s)$ and $\mathrm{D}(s)$. The aggregate employment structure is given by:

$$
\begin{gathered}
n^{\mathrm{s}}{ }_{\mathrm{c}}=[\alpha /(1-\alpha)]\left(\gamma^{\mathrm{u}} / \gamma^{\mathrm{s}}\right)\left(n-n^{\mathrm{s}}\right) \\
n^{\mathrm{u}}{ }_{\mathrm{c}}=n-n^{\mathrm{s}}
\end{gathered}
$$




$$
n_{\mathrm{d}}^{\mathrm{s}}=n^{\mathrm{s}}-\left\{[\alpha /(1-\alpha)]\left(\gamma^{\mathrm{u}} / \gamma^{\mathrm{s}}\right)\left(n-n^{\mathrm{s}}\right)\right\}
$$

The relative wage of the skilled is now low enough to make it worth having them both in knowledge and direct production. A $\mathrm{D}(s)$ sector coexists with a centralized one, $\mathrm{C}(u, s)$, in which all unskilled workers are employed. The corresponding organizational regime is thus denoted $\mathrm{C}(u, \mathrm{~s})-\mathrm{D}(s)$. As $n^{\mathrm{s}}$ increases from $n_{2}^{\mathrm{s}}$ to $n$ the centralized sector shrinks and the decentralized sector expands: an increasing fraction of the labor force is employed in the latter.

Finally, when the entire workforce is skilled $\left(n^{s}=n\right)$ all firms shift towards decentralization. The $\mathrm{D}(s)$ regime then prevails.

In summary, according to our theoretical framework, as the supply of skilled workers increases the economy travels through the following path of organizational change:

$$
\mathrm{D}(u) \rightarrow \mathrm{D}(u)-\mathrm{C}(u, s) \rightarrow \mathrm{C}(u, \mathrm{~s}) \rightarrow \mathrm{C}(u, \mathrm{~s})-\mathrm{D}(s) \rightarrow \mathrm{D}(s)
$$

If we assume that centralized firms mainly produce manufactured goods and that decentralized firms are involved either in agriculture and craft activities or in advanced services our model accounts for long-term changes in work organization. When the general level of education was very low all over what is now the industrialized world, most economies were dominated by small businesses, mainly agricultural and craft, organized on a largely autonomous basis. This corresponds to our $\mathrm{D}(u)$ regime. As the level of education went up in the 19th century vertical division of labor started to develop and gave birth to modern manufacturing, while the rural exodus and industrialization accelerated. Our $\mathrm{D}(u)-\mathrm{C}(u, s)$ regime provides a stylized account of this transition towards a scientific organization of work, as promoted by engineers like Fayol and Taylor. Thus we propose for this period an alternative interpretation to that given by Chandler (1990), who explains organizational change by the development of the railway system and financial markets and by the creation of standards in accountancy. However, he refers to education in many places in his book. When he analyzes British capitalism (Part III, pp. 291-294) Chandler highlights the under-investment in education as compared with Germany or the USA. ${ }^{3}$ This would have slowed down the centralization movement within British firms. Concerning US

\footnotetext{
${ }^{3}$ When he considers the education system Chandler is mainly interested in engineering and business schools. His implicit definition of skills is thus more restrictive than ours as it is focused on higher education. However, secondary school is generally needed to enter university. Moreover, there also exists a vertical division of labor in conception activities (not formalized here) where workers with higher educational attainments are the bosses of other, less educated skilled workers.
} 
capitalism, Chandler describes a situation in which firms' integration and the related rationalization of production and distribution channels created a strong demand for higher education, contributing to the development of universities and schools. As economic development went on and the education level increased in all countries a wholly centralized organization started to dominate. This dates back to the first half of the 20th century and is often referred to as the 'Fordist' regime (Boyer, 1991). It was characterized by a sharp division between conception and execution activities, leading to task specialization on a large scale. This new step towards centralization is accounted for in our model by the $\mathrm{C}(u, s)$ regime, in which all firms finally opt for a centralized organization. Eventually, a new trend in work practices has emerged over the past 20 years which has been characterized by a move towards more decentralization of responsibility in favor of skilled workers. This is particularly the case in advanced information and communication services, where workers are often independent consultants. This is accounted for in our framework by the $\mathrm{C}(u, s)-\mathrm{D}(s)$ regime, in which a rising proportion of the skilled labor force is employed in decentralized firms.

\subsection{Wage Inequality}

As the decentralized mode of organization tends to spread in the economy wage inequality stops decreasing. In the wholly centralized regime the relative wage of skilled workers decreases as they become more numerous, which brings about a steady reduction in inequality. This is no longer the case in the $\mathrm{C}(u, s)-\mathrm{D}(s)$ regime since the proportion of skilled to unskilled workers is now kept constant in centralized firms. As a consequence, the skilled-unskilled wage gap stabilizes and wage inequality stops decreasing (see Figure 3).

This result is consistent with trends in educational wage differentials experienced by most industrialized countries in the 1970s and 1980s. Between 1970 and 1980 the university/high school differential decreased in Canada, Sweden, Japan, France, the USA and UK (Machin, 1996). These decreases ranged from 5 to $15 \%$ according to country and stopped by 1980 . Between 1980 and the early 1990s the educational wage gap remained roughly constant in Canada, Germany, Finland, France and Italy. It increased slightly in the Netherlands and Japan, and rose sharply in the USA and UK (see Gottschalk and Smeeding, 1997). So, all the major industrialized economies had experienced at least a stop in the downward trend of educational wage inequality by the beginning of the 1980s (OECD, 1996).

Our model is consistent with this general stylized fact since wage inequality stops decreasing as the decentralized mode of organization starts spreading in 


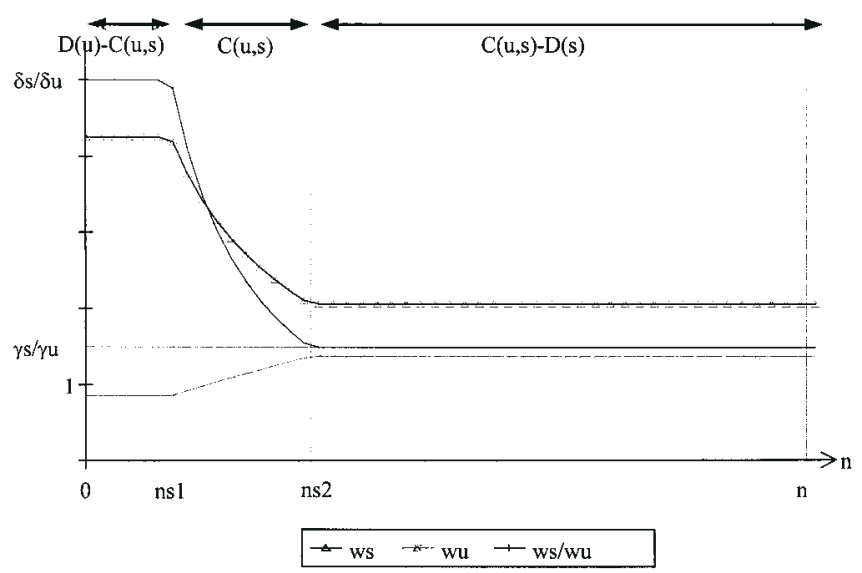

FIGURE 3. Pattern of relative wages

the economy. It does not account for the sharp rise in wage inequality experienced by a small number of countries, such as the USA and UK. This comes as no surprise since in these two countries the increasing wage dispersion seems to have been partly caused by a very different factor from the one modelled here, i.e. the weakening of labor market institutions (Gosling and Machin, 1995; Fortin and Lemieux, 1997). In this respect our model seems to fit better with evidence from continental Europe rather than from Anglo-Saxon economies.

In addition to this account of long-term changes in organization and wages the model provides some testable predictions.

\section{Empirical Implications of the Model}

The model developed above provides two testable predictions. In this section we compare them to some existing empirical evidence and propose some direct tests using French establishment-level data. ${ }^{4}$

\subsection{Skill Supply and Organizational Change}

When considering the organizational path displayed in Figure 2 from a cross-sectional perspective and for developed countries, in which $\mathrm{D}(u)$ has essentially disappeared, the model predicts that the more skilled workers are

${ }^{4}$ These tests draw heavily on joint work with John Van Reenen (see Caroli and Van Reenen, 1999): 'Skill Biased Organizational Change?', CEPREMAP Working Paper 9917. We are most grateful to him for letting us use them here. 
available in an economy (the higher the educational level) the higher the proportion of the labor force employed in decentralized firms. This prediction should be tested on a cross-section of countries. However, if data on educational outcomes are available for a large number of OECD countries data on innovative work practices and organizational change only exist for a small number of countries and cross-country comparisons are still fragile (OECD, 1999). Thus we propose to test our prediction on a cross-section of French region-industry cells. We assume that because of the limited geographical and industrial mobility of most of the workforce the characteristics in terms of education in the firms' local environment has an influence on their organizational behaviour. More precisely, the greater the fraction of skilled workers available in their environment the more likely are firms to introduce new work practices.

In order to test this prediction a reasonable strategy is to consider the impact of the supply of skills in a firm's local environment upon the probability that the latter implement organizational changes $(O C)$. This can be done using a French survey called REPONSE, which provides information on establishments' strategies of organizational change: 2500 establishments were surveyed in 1992 and senior managers were asked whether a series of new work practices had been introduced in their workplace over the period 1989-1992. In the following we consider one particular practice, delayering, which is closest to our theoretical notion of decentralization, and we code establishments as having $O C=1$ when delayering has already been implemented or is in the process of being so (otherwise $O C=0$ ). REPONSE also provides information about establishments' characteristics that may be used as controls in the regression. The annual French labor force survey provides information about educational attainments of the economically active population that can be aggregated at the industry $\times$ region level $(14 \times 21$ cells) and matched with the REPONSE survey. We define the supply of skilled workers in the environment of a given establishment as the share of those workers with a college or high school degree (baccalauréat) in the region and industry where the establishment is located.

The propensity to introduce $O C$ is an unobserved latent variable $y_{i j k}$ so that the empirical model takes the form of a simple probit:

$$
y_{i j k}=\alpha H E_{j k}+\beta \mathbf{x}_{i j k}+\gamma_{1} D_{j}+\gamma_{2} D_{k}+u_{i j k}
$$

where

$$
O C_{i}=1 \text { if } y_{i j k}>0 ; \quad O C_{i}=0 \text { otherwise }
$$


TABLE 1 Supply of Highly Educated Workers and Organizational Change (Delayering) in France (1989-1992)

Organizational change 1989-1992

\begin{tabular}{llll}
\hline & $(1)$ & $(2)$ & $(3)$ \\
High education (\%) & $0.031(0.084)$ & $0.563(0.291)$ & $0.921(0.426)$ \\
Extended controls & No & No & Yes \\
Industry dummies (14) & No & Yes & Yes \\
Regional dummies (21) & No & Yes & Yes \\
Observations & 2112 & 2112 & 1014 \\
Log likelihood & -1461.5 & -1356.8 & -614.5 \\
Pseudo $R^{2}$ & 0.000 & 0.072 & 0.121 \\
\hline
\end{tabular}

These are the marginal effects (and associated standard errors) from a probit maximum likelihood estimation. Extended controls include establishment size, whether the establishment is public or private, whether a union is recognized, how much of the labor force is unionized and whether demand has risen or fallen over the last 3 years.

and $i$ represents the establishment, $j$ the region and $k$ the industry. $H E$ denotes the proportion of workers with a college or high school degree in region $j$ and industry $k$ where the establishment is located, $\mathbf{x}_{i j k}$ is a vector of the establishment's characteristics which are likely to affect a firm's choice of organizational change and $D_{j}$ and $D_{k}$ are regional and industry dummies. Table 1 reports the results of the estimation of equation (E1).

Column 1 displays the raw correlation between local skill supply and the probability that firms introduce organizational change. The coefficient is correctly signed, although not significant at conventional levels. Column 2 controls for industry and regional dummies and the coefficient of the skill variable becomes significant at the $10 \%$ level. Eventually, when estimating the more complete model including a full set of establishment characteristics (column 3) the partial impact of skills upon organizational change rises sharply and becomes significant at the $5 \%$ level. These results support the prediction that the more skilled workers are available in a firm's local environment the higher the probability that these firms will introduce organizational changes leading to more responsibility being awarded to workers.

\subsection{Organizational Change and Firms' Internal Skill Structures}

A second prediction of our model is that as decentralization spreads in the economy a growing fraction of the workforce becomes attached to firms that only employ educated workers, $\mathrm{D}(s)$. Our theoretical framework does not tell us much about the dynamics of skills at the individual firm level during the transition from a centralized to a decentralized model. In fact, this transition 
may take two different forms: (i) the creation of new firms organized according to the $\mathrm{D}(s)$ model while some $\mathrm{C}(u, s)$ firms are destroyed;' (ii) a progressive transformation of $\mathrm{C}(u, s)$ firms into $\mathrm{D}(s)$ ones leading to a sharp drop in the ratio of unskilled to skilled workers. It is rather difficult to measure transition through creation and destruction of firms because newly created as well as newly destroyed firms are harder to survey than older ones. However, available data allows a check as to whether the skill structure of surviving firms becomes more homogeneous when they adopt innovative work practices.

Some empirical studies have already tested such a prediction. The OECD (1999) has investigated the relations between the use of a set of innovative work practices and the required skills of the workforce using the declarations of a sample of establishments from 10 European countries in 1996 (EPOC survey). It appears that establishments with flatter hierarchical structures and those that use teamwork are less likely to have low skill requirements for their workforce. Using US data, both Black and Lynch (1997) and Bresnahan et al. (2001) find that implementation of innovative work practices is more efficient, as measured through their impact on productivity, when the skill level of the workforce is higher. Using data on British establishments in the late 1980s (The Workplace and Industrial Relations Survey, WIRS), Caroli and Van Reenen (1998) show that the proportion of unskilled manual workers in 1990 is significantly lower in those establishments which have delayered over the period 1981-1984.

For French manufacturing three empirical studies have tested the relation between skills and organizational practices. Using a 1987 labor force survey on work organization ('Enquête Techniques et Organisation du Travail', TOTTO), Greenan and Guellec (1998) show that the autonomy of front line workers, as well as the intensity of communication, are both negatively correlated with the share of unskilled manual workers in the firm. The SESSI survey on organizational change ('Enquête Changement Organisationnel'), conducted in 1993, asks firms about the adoption of new organizational practices during the period 1988-1993. Firms that have adopted innovative work practices (autonomous work teams, quality circles or problem solving groups, delayering and/or increased responsibilities for front line workers) more frequently declare that the required skills of their managers, supervisors and blue collar workers have increased (Greenan, 1996a). Matching this survey with a survey on firms' occupational structures ('Enquête Structure des

5 This may happen through the development of start-ups of a $\mathrm{D}(s)$ type which challenge old $\mathrm{C}(u, s)$ firms in their market, but also through the splitting up of $\mathrm{C}(u, s)$ firms into $\mathrm{C}(u, s)$ and $\mathrm{D}(s)$ firms. Downsizing and outsourcing of non-core functions may go along with the latter type of transition. 
Emplois', ESE), Greenan (1996b) shows that firms that have adopted a cluster of innovative work practices have increased their share of executives at the expense of that of clerks. Hence, workplace innovation is conducive to transformed white collar work favoring skills. Eventually, using the REPONSE data set and matching it with the ESE, Caroli and Van Reenen (2001) find that the adoption of innovative work practices subsequently reduces the wage bill share of unskilled manual workers. Over the period 1992-1996 this decreased by 2.3 percentage points, with the introduction of delayering accounting for some $38 \%$ of the fall. This suggests that the introduction of innovative work practices has an important economic (and not only statistical) impact on the reshaping of the occupational earnings structure at the expense of the least skilled workers.

The REPONSE survey can also be used to directly test the relation between skills and organizational change, as senior managers were asked whether there have been increases or decreases in net employment of three groups of workers (managers, intermediate workers and operatives) between 1989 and 1992. This variable being qualitative, we estimate the following probit model:

$$
\Delta n_{i j k}^{\mathrm{s}}=\delta_{1} O C_{i j k}+\delta_{2} \mathbf{x}_{i j k}+\delta_{3} D_{j}+\delta_{4} D_{k}+\varepsilon_{i j k}
$$

where

$$
\begin{aligned}
\Delta n^{s}{ }_{i j k}= & 1 \text { if net employment has increased in } \\
& \text { establishment } i \text { for skill group } s \\
\Delta n^{s}{ }_{i j k}= & 0 \text { otherwise }
\end{aligned}
$$

and $\mathbf{x}_{i j k}, D_{j}$ and $D_{k}$ are defined as in equation (E1). In this specification the skill structure of the workforce is captured through the establishment's occupational structure. A prediction of our theory is that organizational change should raise the proportion of workers employed in more highly skilled occupations. Given the qualitative nature of our data, this would result in $O C$ having a greater positive impact (or smaller negative impact) on employment increases for managers than for operatives. Table 2 presents the regression results.

Organizational change generally appears to be accompanied by downsizing. Its impact upon net employment increases is negative for all categories of workers (although not always quite significant). In the basic specification $O C$ has a negative effect upon net employment of both intermediate workers and operatives at conventional significance levels. The same holds for 
TABLE 2 Probability of Increase in Net Employment and Organizational Change in France (1989-1992)

\begin{tabular}{llll}
\hline & Managers & $\begin{array}{l}\text { Intermediate } \\
\text { workers }\end{array}$ & Operatives \\
\hline Delayering (basic) & $-0.009(0.018)$ & $-0.044(0.017)$ & $-0.078(0.017)$ \\
Observations & 2112 & 2112 & 2112 \\
$R^{2}$ & 0.0001 & 0.004 & 0.011 \\
Delayering (extended) & $-0.027(0.032)$ & $-0.039(0.027)$ & $-0.062(0.028)$ \\
Observations & 1007 & 1007 & 1007 \\
$R^{2}$ & 0.123 & 0.165 & 0.180 \\
\hline
\end{tabular}

The basic regression does not include any controls. The extended regression includes the same establishment controls as in Table 1 (including regional and industry dummies) plus a dummy for whether or not the establishment uses computerized equipment. Standard errors in parentheses.

operatives only in the most general specification. Moreover, in both estimates the (negative) impact of $O C$ is greater for lower qualification groups. In the most general specification the point estimate is -0.062 for operatives whereas it is only -0.027 for managers. So, although $O C$ seems to have a negative impact on net employment increases for all categories, it is more detrimental to the lowest skill groups. This result is supportive of the second core prediction from our model, i.e. the fact that following organizational change skill homogeneity increases at the expense of the least skilled.

Overall, our theoretical model appears to be consistent with preliminary empirical evidence based on French data. A second line of microeconomic tests would investigate the impact of organizational changes on wages paid by establishments or firms. Some work has been done in the US (see Cappelli, 1996) which shows that the introduction of new work practices does not have a clear impact upon wage inequality across skill groups. So far we have not had access to similar data for France but this line of research is definitely challenging and, more generally, the impact of new work practices on pay systems has to be investigated further.

\section{Conclusions}

The model presented here exhibits a sequence of organizational equilibria generated by an increase in the share of skilled workers in the labor force. In parallel a time pattern is generated for skilled and unskilled wages. The model yields three main results.

First, as the proportion of skilled workers increases exogenously in the population the economy travels through three main organizational equilibria: when skilled labor is scarce the organization of firms is rather decentralized; 
as the stock of skills increases the economy progressively shifts to a more centralized regime, before switching back to decentralization when skilled labor is abundant. Such a pattern is consistent with historical evidence. In particular, the past two decades have seen the emergence and diffusion of new modes of organization characterized by a greater autonomy of workers. The increasing share of independent workers and small firms in the labor force is consistent with this trend. Although many studies have stressed the role of technical change (the changing size of increasing returns to scale) as well as institutional factors (competition policies) in this evolution, our model shows that the accumulation of skills stands as another candidate. Second, as a decentralized mode of organization starts to spread in the economy wage inequality stops decreasing. Third, as the economy switches from a centralized to a decentralized regime firms' skill structures become more homogeneous.

Our model suggests some directions for further research. At the empirical level we have provided some limited microeconometric evidence, but the question of long-term macroeconomic trends is raised. In this respect, systematic cross-country comparisons of work practices are called for. Such an approach should hopefully allow the display of 'national systems of organization' in the manner of the national innovation systems characterized by Nelson (1993). This would provide a first step towards assessing the relationships between national educational institutions, organizational configurations and macroeconomic performance.

At a theoretical level, one interesting research avenue would aim at enlarging our definition of organization, so as to take into account the communication dimension. We have defined the centralized and decentralized modes of organization with respect to the degree of autonomy awarded to workers, as well as the range of tasks they perform. This view of organization is somewhat restrictive and does not allow for any difference in the production process at work in $\mathrm{D}(u)$ and $\mathrm{D}(s)$. Workers are perfectly autonomous in both configurations and, in fact, there is little collective work: a firm with $n$ workers is identical to $n$ firms with 1 worker. If this representation may schematically describe the $\mathrm{D}(u)$ firm, ${ }^{6}$ the $\mathrm{D}(s)$ firm is likely to be more complex. As a matter of fact, education increases the ability to formalize and codify knowledge. Skilled workers are not only more efficient in conception activities, they are also more likely to benefit from the knowledge of others through communication. In this sense skills are certainly a more powerful tool than computers in reducing communication costs. When employing a high

\footnotetext{
${ }^{6}$ Of course, if we want a better match with reality the trade guilds typical of the craft industry imply knowledge transfers between the master and the apprentice and forms of subordination that do not correspond to the perfect autonomy that we formalize.
} 
proportion of skilled workers a decentralized firm is more able to insert into communication networks and to benefit from the externalities involved in horizontal information exchanges. So, a general theory of organizational change should aim at combining the approach in terms of autonomy developed here and an approach based on communication. This avenue is still to be investigated.

\section{Acknowledgements}

We are grateful for helpful comments from Philippe Aghion, Andrea Bassanini, François Langot, Costas Meghir and one anonymous referee. Useful suggestions have also been offered by participants to the ESF workshop on 'Employment, Market Integration and Regional Economic Development' (Barcelona, 1996), the ESF Conference on 'Growth and Convergence in Closed and Open Economies' (Lucca, 1997) and seminars at INRA and CEPREMAP. The usual disclaimer applies.

\section{References}

Acemoglu, D. (1998), 'Why Do New Technologies Complement Skills? Directed Technical Change and Wage Inequality,' Quarterly Journal of Economics, 113(4), 1055-1089.

Acemoglu, D. (1999), 'Changes in Unemployment and Wage Inequality: An Alternative Theory and Some Evidence,' American Economic Review, 89(5), 1259-1278.

Aghion, P., E. Caroli and C. Garcia-Peñalosa (1999), 'Inequality and Economic Growth: the Perspective of the New Growth Theories,' Journal of Economic Literature, 37(3), 1615-1660.

Aoki, M. (1986), 'Horizontal vs. Vertical Information Structure of the Firm,' American Economic Review, 76(5), 971-983.

Aoki, M. (1990), 'The Participatory Generation of Information Rents and the Theory of the Firm,' in M. Aoki, B. Gustafsson and O. Williamson (eds), The Firm as a Nexus of Treaties, pp. 26-52. Sage: London.

Aquain, V., J. Bué and L. Vinck (1994), 'L’Évolution en Deux Ans de l'Organisation du Travail: Plus de Contraintes Mais Aussi Plus d'Autonomie pour les Salariés,' Premières synthèses, DARES, no. 46, March.

Atkinson, A. (1997), 'Bringing Income Inequality In From the Cold,' Economic Journal, 107(441), 297-321.

Black, S. and L. Lynch (1997), 'How to Compete: The Impact of Workplace Practices and Information Technology on Productivity,' NBER Working Paper no. 6120. NBER: Cambridge, MA.

Bolton P. and M. Dewatripont (1994), 'The Firm as a Communication Network,' Quarterly Journal of Economics, 109(4), 809-839.

Boyer, R. (1991), 'New Directions in Management Practices and Work Organization,' CEPREMAP Working Paper no. 9130.

Braverman, H. (1974), 'Labor and Monopoly Capital: The Degradation of Work in the Twentieth Century,' New York Monthly Review.

Bresnahan, T., E. Brynjolfsson and L. Hitt (2001), 'Information Technology, Workplace Organization and the Demand for Skilled Labor: Firm Level Evidence,' Quarterly Journal of Economics, in press. 
Cappelli, P. (1996), 'Technology and Skill Requirements: Implications for Establishment Wage Structures,' New England Economic Review, May/June, 139-154.

Caroli, E. and J. Van Reenen (1998), 'Qualifications et Changement Organisationnel: le Cas des Entreprises Britanniques dans les Années 1980,' mimeo. INRA-LEA.

Caroli, E. and J. Van Reenen (2001), 'Skill Biased Organizational Change? Evidence from a Panel of French and British Establishments,' Quarterly Journal of Economics, in press.

Chandler, A. (1962), 'Strategy and Structure,' in The History of the Industrial Enterprise. MIT Press: Cambridge, MA.

Chandler, A (1990), Scale and Scope: The Dynamics of Industrial Capitalism. The Belknap Press: Cambridge, MA.

Fortin, N. and T. Lemieux (1997), 'Institutional Changes and Rising Wage Inequality: Is there a Linkage?, Journal of Economic Perspective, 11(2), 75-96.

Goldin, C. and L. F. Katz (1999), 'Education and Income in the Early 20th Century: Evidence from the Prairies,' NBER Working Paper no. 7217. NBER: Cambridge, MA.

Gosling, A. and S. Machin (1995), 'Trade Unions and the Dispersion of Earnings in British Establishments 1980-1990,' Oxford Bulletin of Economics and Statistics, 57, 167-184.

Gottschalk, P. and T. Smeeding (1997), 'Cross-National Comparisons of Earnings and Income Inequality,' Journal of Economic Literature, 35(2), 633-687.

Greenan, N. (1996a), 'Innovation Technologique, Changements Organisationnels et Évolution des Compétences,' Economie et Statistique, 298, 15-33.

Greenan, N. (1996b), 'Progrès Techniques et Changements Organisationnels: leur Impact sur l'Emploi et les Qualifications,' Economie et Statistique, 298, 35-44.

Greenan, N. and D. Guellec (1994), 'Co-ordination Within the Firm and Endogenous Growth,' Industrial and Corporate Change, 3(1), 173-197.

Greenan, N. and D. Guellec (1998), 'Firm Organisation, Technology and Performance: an Empirical Study,' Economics of Innovation and New Technology, 6, 313-347.

Kremer, M. (1993), 'The O-Ring Theory of Economic Development,' Quarterly Journal of Economics, 108(3), $551-575$.

Kremer, M. and E. Maskin (1996), 'Wage Inequality and Segregation by Skill,' NBER Working Paper no. 5718. NBER: Cambridge, MA.

Lindbeck, A. and D. J. Snower (1996), 'Reorganization of Firms and Labour Market Inequality, American Economic Review, 86(2), 315-321.

Machin, S. (1996), 'Wage Inequality in the UK,' Oxford Review of Economic Policy, 12(1), 47-64.

Marsden, D. and P. Ryan (1991), 'Initial Training, Labour Market Structure and Public Policy: Intermediate Skills in British and German Industry,' in P. Ryan (ed.), International Comparisons of Vocational Education and Training for Intermediate Skills, pp. 251-285. Falmer Press: London.

Nelson, R. R (1993), National Innovation Systems. A Comparative Analysis. Oxford University Press: Oxford.

NUTEK (1996), Towards Flexible Organisations, Vol. 6. Gotab: Stockholm.

OECD (1996), Employment Outlook. OECD, Paris.

OECD (1999), Employment Outlook. OECD, Paris.

Osterman, P. (1994), 'How Common is Workplace Transformation and Who Adopts It?,' Industrial and Labor Relations Review, 47(2), 173-188.

Soskice, D. (1993), 'Social Skills from Mass Higher Education: Rethinking the Company-Based Initial Training Paradigm,' Oxford Review of Economic Policy, 9(3), 101-113.

Thesmar, D. and M. Thoenig (2000), 'Creative Destruction and Firm Organization Choice,' Quarterly Journal of Economics, 115(4), 1201-1237. 